\title{
The Group Interview Experience as a Tool for Admission to Teacher Education
}

\author{
Shosh Leshem \\ Education Faculty, Oranim Academic College of Education, 36006 Tivon, Israel \\ Correspondence should be addressed to Shosh Leshem, shosh-1@zahav.net.il
}

Received 6 March 2012; Revised 2 May 2012; Accepted 17 May 2012

Academic Editor: Eric Z. F. Liu

Copyright () 2012 Shosh Leshem. This is an open access article distributed under the Creative Commons Attribution License, which permits unrestricted use, distribution, and reproduction in any medium, provided the original work is properly cited.

This study deals with qualitative aspects of group interviews as a tool in selecting students for a teacher education program. It presents findings from insider research on the dynamics of group interviews, focusing on participants' experiences and the meanings they attribute to them. The aim of the study is to gain a better understanding of the group interview as an effective tool for the selection of candidates for teacher education. The participants were 107 candidates in ten groups. Data from observations, interviews, and questionnaires were gathered to examine variables that affect the performance of the candidates in the interview. The findings highlight the complexities of group interviews as a filtering tool, foremost cultural and social aspects that affect assessors' and participants' performance. Notwithstanding the complexities, the findings demonstrate the utility of the group interview in filtering out unsuitable candidates and, possibly, in marketing the institution.

\section{Introduction}

Teacher education and the teaching profession are in crisis in many Western countries [1,2] including Israel [3]. The perceived low status of the teaching profession impinges on the quality of applicants to teacher education institutions and, in turn, elicits constant criticism of teacher educators from education administrators and parents, who blame them for failing to produce effective teachers $[2,3]$. In the past two decades, the debate about educational reforms has led to the call for "new" teacher education in Israel $[1,2]$. Zimpher and Howey [4] suggest that one of the requisites for the improvement of teacher education is the recruitment of highly qualified candidates for the teaching profession. Consequently, universities and colleges are becoming more selective among candidates and requiring higher grade point averages for admission to their teacher education programs.

However, there seems to be no professional consensus about the reliability of academic indicators in the selection process $[5,6]$. Research findings repeatedly demonstrate that such criteria are poor predictors of eventual success in teaching [7]. Research has identified qualitative issues as more effective indicators in this regard [8]. Findings among teachers in Israel and in the USA suggest that a group interview process offers much potential in the selection of promising classroom teachers [9]. A group interview may identify three major skills of a quality teacher: communication, affective skills, and leadership skills. It has been found that candidates who have these traits perform well [10].

This study was conducted at Oranim Academic College of Education in Israel that uses group interviews to select candidates for admission to its teacher education program. The study was prompted by recent dilemmas among stakeholders in the program concerning the validity and reliability of group interviews as a screening tool for prospective teachers and by appeals from rejected candidates who claimed that the interview failed to reflect their interpersonal skills and verbal ability. Some of the appeals exposed cultural and social subtleties that could not be ignored.

The research task, then, was to shed light on the experiences of the candidates and the facilitators. To accomplish this, the researchers sought to understand how participants perceive the group interview, what meanings they attribute to the process, and how the interview situation affects their performance in the interview. Studies on group interviews 
are scarce; their main concern is the investigation of predictive factors of success $[10,11]$. There is a lacuna in research in explaining the dynamics within the group and their impact on individual participants' performance. Hence, this study contributes to our knowledge of group interviews as a tool for admission to teacher education.

\section{The Literature}

2.1. Quality of Teachers and Teacher Education. The quality of teachers and of teacher education has long been an issue of concern in many countries. Questions relating to the characteristics that "good" teachers "must" possess and how they should be instilled have challenged many teacher education programs around the world [12]. Indeed, Cochran-Smith maintains that "The question of how the nation's teachers are recruited, prepared, and retained has become one of the hottest topics in the public and academic discourse regarding education" (page 4). Cochran-Smith goes so far as to call for a "new teacher education" in response to the implications of evolving social, economic, professional, and political trends in the approach to teacher education. Although her recommendation pertains to the USA education system, it is relevant to the Israeli educational context as well.

If so, what are the characteristics of the "good teacher" that teacher education programs should seek in its applicants? How can this knowledge facilitate the selection of the future successful teachers? These are generic questions that are regularly asked of applicants by interview panels. The perceptions of a "good teacher," however, are quite diverse and inconclusive. In a recent study at the college student teachers and mentors were asked about their perceptions of "good teaching." They specifically emphasized the interpersonal aspect of teaching: good teachers care, know their pupils, and teach with emotion, love, and excitement [13]. There is also evidence of a difference in perception between younger and older students: the former tend to perceive the personality of the teacher as dominant and the latter are more respectful of knowledge and teaching proficiency [14]. Much earlier, Shechtman and Godfried [15] identified three dimensions of teaching that relate to effective teaching: verbal, interpersonal, and leadership skills. Most teacher education programs, however, focus on academic criteria (grades) to select the most suitable candidates [16]. There have been attempts, such as psychological tests, to predict success in teaching by measuring candidates' affective characteristics, but they reported mixed results [17].

Shechtman [6] examining the contribution of the assessment of interpersonal behavior to the prediction of initial teacher success, writes "Clear communication with students, which is a central factor in the teaching-learning processes, requires oral intelligence and entails both clarity of thinking and verbal expressiveness" (page 243). She also mentions the importance of self-confidence in enhancing human interaction skill, leadership qualities, and flexibility. More recent studies $[14,18,19]$ support this finding and maintain that older as well as younger students attribute importance to the teacher's personality and his/her attitude toward the students. Research has also shown that the dialogic nature of the teacher-student relationship is important among the qualities attributed to the "good teacher" [20]. These, then, according to the literature, appear to be the essential qualities that the admission testing process should identify in tomorrow's "good teachers." The remaining question in this study is whether the group interview is the optimal setting in which to identify them.

2.2. Pros and Cons of Personal Interviews. Most research on interviews focuses on personal interviews in the contexts of hiring and medical schools [21]. Indeed, the personal interview is one of the most widely used selection techniques in the medical and dental school admission process. Its goal is to screen out those candidates whose personality does not seem suitable for medical or dental studies. Between $10 \%$ and $20 \%$ of otherwise qualified candidates are rejected on the basis of such interviews [22, 23]. According to Weiss et al. [22], however, the personal interview is somewhat disappointing as a separate predictor of personality traits. They found that matriculation scores are better predictors not only of academic criteria but also of personality characteristics.

Gafni and Mohinsky [23] conducted research among dental school candidates in Israel to see whether the replacement of the interview with an objective group questionnaire would enhance standardization and objectivity and, in turn, avoid the possible biases of the interview-a topic that will be of concern to us below. They suggest that the questionnaire may complement the interview as a prescreening tool [23]. At another medical school, facilitators' comments were recorded and qualitatively analyzed to identify specific aspects of the nature of the interview. The most striking finding was the incomparability of recorded material across facilitators. Some facilitators commented on the candidates' academic qualifications, an aspect with which the interview was not supposed to deal. This gave the facilitators latitude to explore unique areas of their own interests in candidates' qualifications [24].

Ben Shachar and Beller [25] claim that the validity of the interview as a predictive tool to success is very low, even under optimal conditions with the same facilitators usedan impossible condition when there are large numbers of candidates. They define interviews as complex social situations whose outcomes often depend on facilitators' mannerisms and actions. Furthermore, facilitators who conduct interviews are impressed by different aspects of candidates such as appearance, the way they respond to questions, and verbal ability [25].

Another study, investigating variations among interviewers in oral interview tests among teachers of English also points to unfair situations that interviewer variation may cause. The study clearly illuminates a possible relationship between characteristics of interviewer behavior and specific components of language ability affected [26]. The evidence supports the contention that it is difficult to separate distinct personality factors from those related to intelligence 
or culture; hence, the effectiveness of the interview as a screening tool is contested among researchers [25].

Studies conducted in Israel suggest that interviews are potentially useful in the selection of promising teachers $[9,10]$. They also support previous findings that academic criteria are not necessarily good predictors of successful teachers. In a study in an EFL context, Orland-Belleli and Mazor [27] found that the interview is a more effective predictor of success in practice than achievement tests in theoretical subjects.

2.3. Pros and Cons of Group Interviews. Group interviews are growing in popularity as a selection tool in organizations [28] and in university admissions [29]. However, there is very little literature on the topic [30]. A positive aspect of group interviews, as reported by research, is cost efficiency due to the elimination of most of the expense, time, and training of large numbers of facilitators [31]. The negative aspects noted are the lack of accurate information obtained from the candidate and the possibility that candidates may feel apprehensive, self-conscious, and stressed, and consequently may perform poorly, due to lack of privacy [32].

Some researchers suggest that the focus in research should be the added value of the interview compared with other screening methods in use [22]. This is supported by a later research project by Levi-Feldman and Libman [21] conducted at an Israeli teacher education college that investigated three main issues: how the interview as a screening tool was used (a qualitative approach), the validity and reliability of the interview as a qualitative screening tool, and predictability of success (a quantitative approach). The study found that the interview offered no significant predictability of success. The participants did agree, however, that the interview had added value in other respects that other more standardized tools cannot measure.

In a later study on group interviews in an American academic institution, it was found that the validity of group interviews was weak because the facilitators were under greater pressure to multitask during the interview and, consequently, less able to accurately assess each candidate simultaneously. Also, the order in which the candidates responded had a significant effect on the quality of their responses because they "borrowed" responses from other candidates [32].

\section{The Study}

Insights from stake-holders' experiences and observations at the teacher education program at the college suggested that the heterogeneous makeup of the groups may have influenced the participants' experiences and affected the facilitators' judgment. Thus, the study sought to understand the dynamics that unfold within the interview.

The methodology employed essentially falls within the qualitative paradigm, involving an interpretive naturalistic approach that attempts to make sense of phenomena in terms of the meanings that people attach to them $[33,34]$. Just the same, some quantitative data are provided to describe the subjects and obtain a deeper understanding of connections between aspects that were assumed to have an influence on the group dynamics.

\section{The Interview}

Interviews are conducted at the college toward the end of the academic year. After applicants' academic qualifications are scrutinized, 10-12 candidates are invited to be interviewed. They are informed that they should expect to participate in a group interview lasting approximately two hours. A round table is used so that the participants can see each other's name tags for ease in addressing each other. Each interview is facilitated by two members of the teacher education faculty.

The interview consists of four parts. Part 1 involves an introductory task: each candidate is asked to choose an object that best represents them or introduce themselves through a person who knows them well. Part 2 involves a written task in which participants have to respond to an educational dilemma that should illustrate their analytic ability, reflectivity, and creativity. In this twenty-minute task, candidates are asked to read aloud the answer to the last question, in which they had to write a different ending to a story in a text.

In Part 3, the group is divided into two heterogeneous subgroups on the basis of the facilitators' initial impressions of the candidates. Each group is observed by one interviewer who takes notes on the proceedings but does not participate in the discussions. The twenty-minute activity is a simulation based on a debatable issue that emerged from the written text in Part 2. Individuals in each group assume roles to act out the situation and perform four tasks that accompany their role playing. After completing the activity, the subgroup has to present its conclusions. Facilitators discuss their observational feedback with each of the groups.

In the fourth and last part, each participant sums up in public his/her experience by expressing one impression or insight that captures what s/he will take away from the experience.

The facilitators assess the candidates on a five-point scale: very good, good, mediocre, weak, and very weak. The criteria for this ranking are written verbal ability, oral verbal ability, level of thinking, interpersonal communication, leadership, and reflectivity. The facilitators then decide if a candidate should be accepted, rejected, or invited for a follow-up personal interview. Most candidates who are invited to personal interviews are those about whom the two facilitators have some sort of doubt or disagreement.

\section{Methods}

In all, ten groups participated in the research. An eight-item questionnaire was distributed to 107 candidates at the end of the group interview. The candidates were assured that the questionnaire was voluntary, anonymous, and not part of the interview, and that their responses to it would not affect the assessment process. These assurances yielded a 100\% response rate. Each item was divided into two parts. In the 
first part, candidates had to rate from 1 to 5 their attitudes toward a particular aspect of the interview. In the second part, they were asked to provide verbal written comments on each question. The author attended the interview research as a participant-observer [35] and recorded observational notes of verbal and nonverbal accounts from each group interview.

The author interviewed the facilitators after every of their interviews to elicit their immediate impressions and validate the observational data. A qualitative analysis was used to uncover themes emerging from the interviews, the observational notes, and open-ended questions [36]. The data were first coded to generate repeated themes from the meanings and interpretations that the participants attributed to their experiences and observations; then, categories were extracted from the themes. The process was ongoing, with continual comparison of categories to seek meaning within the data and identify relationships so that a theoretical elaboration of the categories could emerge. The scaled responses were analyzed to yield descriptive aspects of candidates' characteristics and candidate attitudes toward the interview that complemented the qualitative data.

Since the study sought to develop theory rather than to test theory, the outcome displays high validity $[37,38]$ and low reliability. Therefore, the conclusions drawn from one particular college of education cannot be generalized, but they do permit the advancement of grounded propositions that other researchers may wish to test in their own contexts [39].

\section{Participants}

6.1. Candidates. The candidates were 19-44 years of age, with an average age of 24 . Most candidates (78.4\%) were female. Hebrew was the first language of $71.7 \%$ of the candidates and $19.8 \%$ of the candidates spoke Arabic as their first language. The rest spoke other languages (Russian, English, Amharic). Most candidates were Jewish (76.2\%). Moslems constituted the second largest religious group (12.1\%) and the rest were Druze or Christian. Most candidates were single $(85.4 \%)$.

The candidates were asked about previous teaching experience, an important variable due to its possible effect on candidates' performance. $24.3 \%$ of the candidates admitted to having no experience in teaching. The remaining $75.7 \%$ claimed to have some experience in various educational roles such as private tutors, youth movement leaders, or instructors in the army.

6.2. Facilitators. All ten facilitators were lecturers at the college, in different faculties. Their ages ranged from 35 to 60. Their specialized disciplines were educational psychology, sociology, literature, special education, communication, education, and history. All attended a one-day preparatory workshop to acquaint them with the group interview procedures. The workshop was conducted by one of the most experienced facilitators, an educational psychologist who had been involved in the design and conduct of the group interviews for approximately ten years.

\section{Findings}

7.1. Candidates' Attitudes towards the Interview Process. The candidates were asked to rate each task according to its difficulty on a Likert scale from 1 (easy) to 5 (hard). They perceived the interview as fairly easy. The summary task was perceived as the easiest (mean $=1.71)$ and the role task (group activity/role play) as the hardest ( mean $=2.19$ ).

The explanations provided in the open questions elicited a deeper picture. Some candidates found the introductory task, in which they had to introduce themselves through a third person or through an object, "embarrassing," "difficult," or "stressful." Their uneasiness stemmed mainly from the fact that they had to "open up" in front of strangers or observe themselves through others' eyes. The majority, however, reported positive feelings. The following extracted quotations represent their views. One candidate wrote: "It was interesting to think of myself this way and also to listen to stories of others." Some felt that the introductory task was "an icebreaker, a creative and interesting task that allowed openness and created a good atmosphere in the room." As for the writing task, most found it "interesting" and its content "easy to identify with."

Some found the role-playing somewhat difficult because it forced them to interact with strangers. "It was a bit disturbing to play roles with people you don't know and to have to impress the facilitators. It was quite intimidating." A few felt that courtesy impeded the dynamics of the discussion: "At times, I had the urge to interrupt and say something but I was conscious of being watched and did not know how it would be interpreted. It is also against my codes of behavior."

In the summary task the candidates were asked to express what they took away from the experience. Most indicated that the experience was insightful and encouraging. They assessed the facilitators' feedback as an "eye-opener" and were pleased to meet real educators as representatives of the staff. For some, the experience "reinforced" the decision to take up teaching: "I'm even more convinced now that I made the right decision. I'm certain now that I'd like my dream to come true."

The interaction with other members of the group seemed to have a strong impact on the candidates. It made them think, as one of the participants described: "Even though you think you have a very clear view on things, you hear other voices and it raises doubts about your own assumptions." It also gave them a feeling that they were in "good company": "I enjoyed sitting with high quality people and listening to what they have to say. It's encouraging to see others who wish to influence and be agents of change." An Arab girl described her insight from a cultural point of view: "In my milieu, teaching is a profession for girls because it's a convenient job. I want to change that concept. I want to be a teacher not out of convenience but out of passion. I'm glad to have met other people who have such passion."

The supportive atmosphere and the power of "the group" also figured prominently in the responses: "I am amazed at how I felt so quickly that I had known these people for quite 
some time. I feel as if I have gained new friends even though I have known them for only a little more than two hours." Very few candidates (five) expressed opposite insights, saying that the experience had made them feel a bit shaky about their decision or that they felt they "did not belong." One of them was quite direct: "I am leaving more confused than when I came in. I am more doubtful than before and I am not sure that "education" is really my mission in life. The educational issues that emerged in the discussions didn't grab my interest."

The candidates were also asked to indicate the level at which they succeeded in expressing themselves and the extent to which they felt comfortable during the interview, on a scale of 1 (not at all) to 5 (very much). The results show that the general ability to self-express and the comfortable feelings in the interview were rather high (mean $=3.84$ and 4.17 , resp.). Candidates expressed a feeling of comfort and said that they "did not feel they were in an interview." They described the atmosphere as "encouraging," "tolerant," "respectful," and "fun." Some mentioned lack of time as a debilitating factor: "There was much more to say but I didn't have enough time to express myself." "It was quite a challenge to listen, process the information, and come up with an appropriate response in a very short time." Those who felt slightly tense said that their talk had been interrupted by their peers and had preferred to remain quiet because they did not wish to seem abrupt. One participant said that she usually talks when she has to and "does not like to interrupt others when they're in the middle of talking." Another candidate said, "I do not feel the need to stand out" and preferred to listen to others.

There were remarks about the presence of three professionals (the two facilitators and the researcher) in the room; some felt this to be intimidating. One candidate expressed this quite vividly: "I felt that so many eyes are watching me and assessing everything I was doing or saying. It was a bit scary. I felt like under a microscope."

7.2. Follow-Up Observations. By the end of the first semester, we were curious to inspect the end-of-term evaluation reports of the candidates (now the students) who had participated in the interviews. We found that ten of the 107 students were defined by the lecturers who had taught them in the first semester as "weak," "need special attention," or "have language difficulties." Four of the 107 failed to achieve a passing grade.

We then went back to the interview files and examined these students' postinterview evaluation reports to see how they matched the students' performance. We found that all the students at issue had received low ratings. Two of the students who failed their courses had initially been rejected by the facilitators in the group interview but appealed and were later accepted on the basis of a personal interview. Although these observations deserve more rigorous and large-scale investigation, they reinforce the notion that the group interview is effective in identifying those candidates who are unsuitable for teacher education.

\section{Discussion}

8.1. The Complexities of Group Interviews. The facilitators in this study agreed unanimously that group interviews can identify "unsuitable" candidates for the teaching profession. Still, the complexities that emerged in the admission panels provoked some concerns among faculty members and gave them food for thought. The following two examples describe some of these complexities, with emphasis on ambiguity.

A candidate wishing to take courses in one of the sciences made a positive impression on the facilitators in the first part of the interview, in which he had to introduce himself to the group. In the role play, however, this impression was completely distorted when he had to interact with his peers in a simulation task. The facilitators' impression then was that his interpersonal communication behavior was irritating, domineering, rude, and aggressive. Accordingly, the facilitators decided that he was not a suitable candidate for teacher education. Due to his strong academic qualifications, however, he appealed and was invited to a personal interview. In this setting, where group communication skills cannot be demonstrated, he again managed to impress the interviewer with his articulacy and high academic level. The admission panel, however, advised him not to seek enrollment as a student of teaching.

Another very highly qualified candidate displayed an aggressive demeanor throughout the interview. At first, the facilitators traced this to excessive self-confidence and perfectionism. In the role play, however, they were convinced that there was much more to it but could not "put their finger on it." They invited the candidate to a personal interview. The interviewer's report advised categorical rejection as the personal interview had exposed personality problems that reinforced the initial decision.

In addition, several Arab girls admitted to having been pressured, tongued-tied, and unable to perform at their best in the group: "Being in a situation where most of the people are more experienced, articulate in Hebrew, and familiar with the "name of the game" isn't easy to cope with. We've never had such an experience before." This may also support Ruggiero's et al. [31] view that a group format may increase candidates' anxiety, mitigate their openness, and diminish the quality of performance. In these situations, certain generic questions arise: how reliable is the group interview in determining a person's suitability for admission to teacher education? To what extent is the interview culturebound? And to what extent are the outcomes of the group interview process determined by the social composition of the group? These questions, emerging from the above cameos, correspond with Ben Shachar and Beller's [25] claim that it is indeed difficult to separate personality factors from those related to culture or intelligence in such situations.

Studies of spontaneous interaction in various interactive contexts highlight the reciprocal influence of communication and context [40]. This follows Bourdieu's notion of tacit communicative style, that is, habitus [41]. People involved in social interaction adjust spontaneously to the prevailing style of communication and to the context. In this study, this was portrayed in the tacit communication style of candidates 
who seemed to adjust by "reading the map" and attuned easily to the situations that emerged. This was especially evident in the simulation part of the interview, where they had to interact with other members in their group. The candidates who performed best were usually those who had had similar life experiences in the army or in serving the community. Tannen [42] terms this "harmonizing," claiming that participants involved in friendly, sympathetic interaction spontaneously harmonize their communicative style with each other and with the context in which they are situated. Thus, even though lively discussion within the group was maintained, "harmonizing" created an imbalance in turn-taking and doomed some participants to the sense of being outsiders.

Communication styles usually "reflect implicit and explicit beliefs, values, representations and environmental constraints..." [34, page 299]. This view supports the evidence exhibited by those candidates who had linguistic constraints or were reluctant to take turns. Tannen [42] distinguishes between speakers of "high considerateness style" and speakers of "high involvement style." The former avoid talking at the same time, have long pauses, and wait for their turn; the latter talk simultaneously with shorter pauses. In some environments, overlapping talk indicates rudeness and dominance; in others, it may indicate involvement and interest [40]. The different meanings attributed to these interaction styles may cause the facilitators to misinterpret the situation. The "disorder" caused by the different styles of communication may be debilitating for some candidates and may enhance communication for others. This corresponds to some of the experiences that the candidates described and may have been another cause of imbalance in communication styles. The question that emerges from the foregoing is how these tacit communication styles influence facilitators' judgment.

The study also showed that different facilitators were impressed by different aspects and that their impressions focused on different points. Facilitators were inclined to explore areas of their own interests in the candidates. Some facilitators put more weight on verbal ability; others focused on interpersonal competency and reflective capacity. The educationalists, for example, looked for "the spark in the eyes"; the psychologists probed cognitive and reflective aspects. Facilitators also had different interviewing styles. Some assumed the role of "teachers" and provided feedback in a "teaching" style, incorporating psychological and educational theories commensurate with their respective disciplines. This mode of interaction usually inspired thinking and led to a lively discussion that exposed the candidates' level of thinking. Candidates interviewed by such facilitators said that they became so involved that they sometimes forgot that they were in an interview; equally, the facilitators said that they enjoyed the discussion. Their enthusiasm created a pleasant atmosphere that candidates went out of their way, in their written accounts, to define as something that reduced tension. Other facilitators were more formal and their feedback was more controlled. Thus, the interviewing style and the amount of feedback may have affected the discourse in the interview session $[24,25]$.
Despite these complexities, the evidence produced in this study suggests that the group interview may have added value as a marketing device. For all candidates, the interview was the first encounter with the institution, one that, overall, gave them a positive impression of the college and its staff. Meeting other candidates who had chosen to take up teaching was encouraging and welcoming, as one of the candidates said: "I already have the urge to learn more about educational dilemmas. I can't wait to start. If all lecturers are like the ones we met today, this is where I want to study." Viewed from a marketing perspective, the group interviews may actually become the institution's "calling card" and a powerful tool for recruitment in teacher education. For the researcher, this finding provided an unexpected insight into the group interview process.

\section{Conclusion}

The study emerged from the need to expand our understanding of the group interview as an instrument for admission to teacher education. Although this study was small in scale and its inductively produced findings cannot be generalized, it contributes to previous research by offering an insider research-based view of interaction processes in group interviews. More specifically, it investigated the meanings that participants attribute to the process and how it affects their performance.

The evidence reported above demonstrates that the group interview is an intensive social encounter that weaves a complex web of communication styles that may convey ambiguous messages. Facilitators and candidates arrive with their own beliefs, values and experiences which inevitably affect the way they perform in a constrained reality. This may foreshadow candidates who do not perform at their best due to cultural or social codes of behavior. Consequently, one may advance the proposition that social, cultural, and personality factors influence candidates' performances in group interviews. If so, the group interview may not be the best and most accurate filtering tool for the selection of suitable candidates. However, the evidence also shows that the group interview has the added value of exposing communication indicators that may not be revealed otherwise; thus, it may be effective in identifying the extreme cases that are unsuitable for teacher education.

The practical implications of the study relate to various internal policies that a college needs to adopt and implement. Facilitators need to be aware of the subtleties inherent in the social and cultural composition of candidate groups and how they affect participants' performance and group dynamics. They should also be sensitive to, and aware of, their own possible influence on the participants' performance. By implication, training workshops for facilitators should be enhanced using case studies and critical incidents to unravel beliefs, and expectations as points of departure for improvement. Similarly, more thought should be devoted to how the groups are composed. It has also been suggested that complementary methods of candidate assessment should be implemented. For example, students who pass the interview 
assessment and are accepted but receive low ratings from the facilitators should be reevaluated by the end of the first semester.

The study shows that the pleasant ambience of the group interview may serve as a "calling card" for the institution. Although the group interview has not been empirically proved to yield better applicants than an alternative procedure, it is worth preserving.

This study, conducted at one college, makes a modest contribution to the existing research on interviews as a tool for the selection of prospective teachers. For teacher education programs in other settings that have similar cultural makeup, it provides food for thought in the pursuit of further research that may generate more insights on how to recruit suitable candidates for the teaching profession. Specifically, more research is needed on the predictive aspects of group interviews on students' success in teacher education courses and practice.

\section{References}

[1] M. Cochran-Smith, "The new teacher: for better or for worse?" Educational Researcher, vol. 34, pp. 3-17, 2005.

[2] P. Grossman, "Responding to our critics: from crisis to opportunity in research on teacher education," Journal of Teacher Education, vol. 59, no. 1, pp. 10-23, 2008.

[3] D. Kfir and T. Ariav, Eds., The Crisis in Teacher Education: Reasons, Problems and Possible Solutions, Van Leer Jerusalem Institute/Hakibbutz Hameuchad Publishing House, Tel Aviv, Israel, 2008.

[4] N. L. Zimpher and K. R. Howey, "The politics of partnerships for teacher education redesign and school renewal," Journal of Teacher Education, vol. 56, no. 3, pp. 266-271, 2005.

[5] J. H. Applegate, "Teacher candidate selection: an overview," Journal of Teacher Education, vol. 38, pp. 2-6, 1987.

[6] Z. Shechtman, "The contribution of interpersonal behavior evaluation to the prediction of initial teaching success: a research note," Teaching and Teacher Education, vol. 5, no. 3, pp. 243-248, 1989.

[7] M. K. Baskin, S. M. Ross, and D. L. Smith, "Selecting successful teacher: the predictive validity of the urban teacher selection interview," The Teacher Educator, vol. 32, pp. 1-21, 1996.

[8] G. J. Petersen and K. M. Speaker, "An examination of admission criteria to programmes o teacher education," in Annual Meeting of at the Mid? Western Educational Research Association, Chicago, Ill, USA, 1996.

[9] Z. Shechtman, "A group assessment procedure as a predictor of on-the-job performance of teachers," Journal of Applied Psychology, vol. 77, no. 3, pp. 383-387, 1992.

[10] D. A. Byrnes, G. Kiger, and Z. Shechtman, "Evaluating the use of group interviews to select students into teacher-education programs," Journal of Teacher Education, vol. 54, no. 2, pp. 163-172, 2003.

[11] J. B. Farnsworth et al., "Selecting the best teacher candidates: can a group interview help?" Education, vol. 124, no. 2, pp. 341-346, 2003.

[12] M. Cochran-Smith, "Sticks, stones and ideology: the discourse of reform in teacher education," Educational Researcher, vol. 30, no. 8, pp. 3-15, 2001.

[13] Author, "Mentoring in the practicum as an interplay of perceptions: a case of an in-service teacher education programme".
[14] S. Arnon and N. Reichel, "Who is the ideal teacher? Am I? Similarity and difference in perception of students of education regarding the qualities of a good teacher and of their own qualities as teachers," Teachers and Teaching, vol. 13, no. 5, pp. 441-464, 2007.

[15] Z. Shectman and L. Godfried, "Assessing the performance and personal traits of teacher education students by a group assessment procedure: a study of concurrent and construct validity," Journal of Teacher Education, vol. 44, no. 2, pp. 130138, 1993.

[16] M. Haberman and L. Post, "Teachers for multicultural schools: the power of selection," Theory into Practice, vol. 37, no. 2, pp. 96-104, 1998.

[17] F. Chang, "School teachers' moral reasoning," in Moral Development in the Professions, J. R. Rest and D. Varvaez, Eds., pp. 71-83, Lawrence Earlbaum, Hillsdale, NJ, USA, 1994.

[18] J. Lowman, Mastering the Techniques of Teaching, Jossey-Bass, San Francisco, Calif, USA, 1995.

[19] N. Hativa, "Is there an easy way to ensure excellence in teaching," Al Hagova, vol. 2, pp. 12-17, 2003 (Hebrew).

[20] A. Cook-Sather, "Reinforming the conversation, student position, power and voice in teacher education," Radical Teacher, vol. 64, pp. 103-125, 2002.

[21] I. Levi-Feldman and Z. Libman, "The interview as a screening tool in a teacher education college," Dapim, vol. 37, pp. 41-64, 2004.

[22] M. Weiss, I. Lotan, H. Kedar, and G. Ben-Shakhar, "Selecting candidates for a medical school: an evaluation of a selection model based on cognitive and personality predictors," Medical Education, vol. 22, no. 6, pp. 492-497, 1988.

[23] N. Gafni and A. Moshinsky, "An objective group questionnaire as a substitute for a personal interview in the admissions process to a dental school," in Annual Meeting of the American Educational Research Association in New Orleans, 2002.

[24] C. L. Elam, M. M. S. Johnson, H. J. Wiese, J. L. Studts, and M. Rosenbaum, "Admission interview reports: a content analysis of interviewer comments," Academic Medicine, vol. 69, no. 10, pp. S63-S65, 1994.

[25] G. Ben Shachar and M. Beller, "The personal interview as a screening tool," Megamot, vol. 35, no. 2-3, pp. 246-259, 1993 (Hebrew).

[26] F. Nakatsuhara, "Inter-interviewer variation in oral interview tests," ELT Journal, vol. 62, no. 3, pp. 266-275, 2008.

[27] L. Orland-Belleli and E. Mazor, "Can we foresee? Gauging students' future success or failure," Trends, vol. 5, pp. 34-43, 1996.

[28] L. Kyriadides and K. L. Kelly, "The impact of engagement in large-scale assessment on teacher? professional development: the emergent literacy baseline? assessment project," Journal of Research in Childhood Education, vol. 18, pp. 18-36, 2004.

[29] M. A. Campion, D. K. Palmer, and J. E. Campion, "A review of structure in the selection interview," Personnel Psychology, vol. 50, no. 3, pp. 655-702, 1997.

[30] R. L. Dipboye, B. B. Gaugler, T. L. Hayes, and D. Parker, "The Validity of unstructured panel interviews: more than meets the eye?" Journal of Business and Psychology, vol. 16, no. 1, pp. 3549, 2001.

[31] K. J. Ruggiero, D. W. Smith, R. F. Hanson et al., "Is disclosure of childhood rape associated with mental health outcome? results from the national women's study," Child Maltreatment, vol. 9, no. 1, pp. 62-77, 2004.

[32] T. Tran and M. C. Blackman, "The dynamics and validity of the group selection interview," Journal of Social Psychology, vol. 146, no. 2, pp. 183-201, 2006. 
[33] N. K. Denzin and Y. S. Lincoln, Handbook of Qualitative Research, Sage, Thousand Oaks, Calif, USA, 1994.

[34] J. W. Creswell, Qualitative Inquiry and Research Design: Choosing among Five Traditions, Sage, Thousand Oaks, Calif, USA, 1998.

[35] J. Sanger, The Compleat Observer? A field Research Guide to Observation, The Falmer Press, London, UK, 1996.

[36] M. B. Miles and A. M. Huberman, Qualitative Data Analysis: An Expanded Sourcebook, Sage, London, UK, 2nd edition, 1994.

[37] A. L. Strauss and J. Corbin, Basics of Qualitative Research: Grounded Theory, Procedures and Techniques, Sage, Newbury Park, Calif, USA, 1990.

[38] J. Mason, Qualitative Researching, Sage, London, UK, 1996.

[39] R. K. Yin, Case Study Research: Design and Methods, Sage, Beverly Hills, Calif, USA, 1984.

[40] M. Gratier, P. M. Greenfield, and A. Isaac, "Tacit communication style and cultural attunement in classroom interaction," Mind, Culture, and Activity, vol. 16, pp. 296-316, 2009.

[41] P. Bourdieu, The Logic of Practice, Stanford University Press, Palo Alto, Calif, USA, 1990.

[42] D. Tannen, Conversational Style: Analyzing Talk among Friends, Ablex, Norwood, NJ, USA, 1984. 


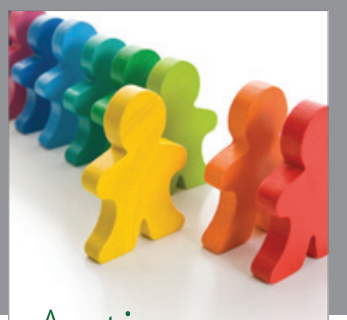

Autism

Research and Treatment
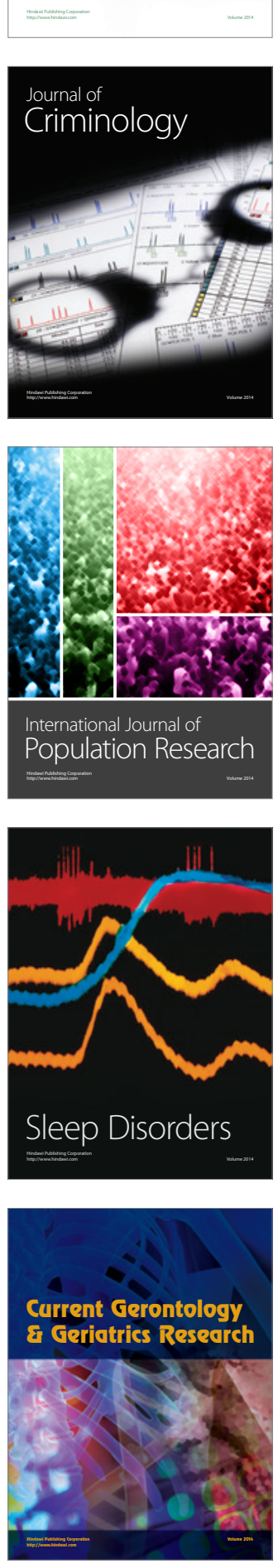
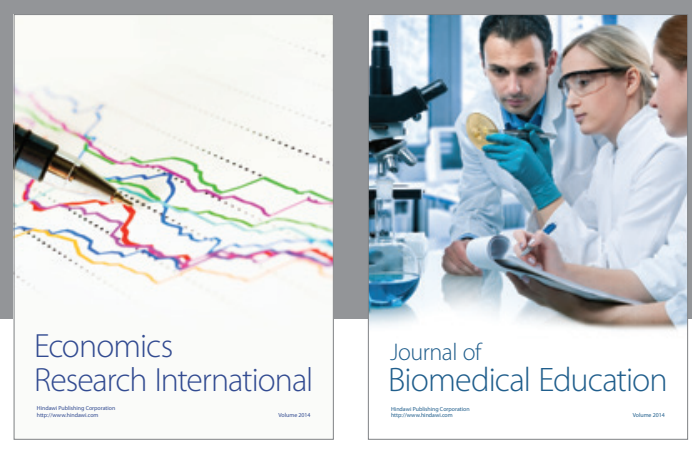

Journal of

Biomedical Education

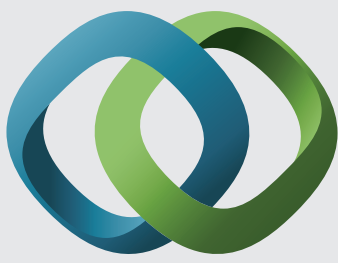

\section{Hindawi}

Submit your manuscripts at

http://www.hindawi.com
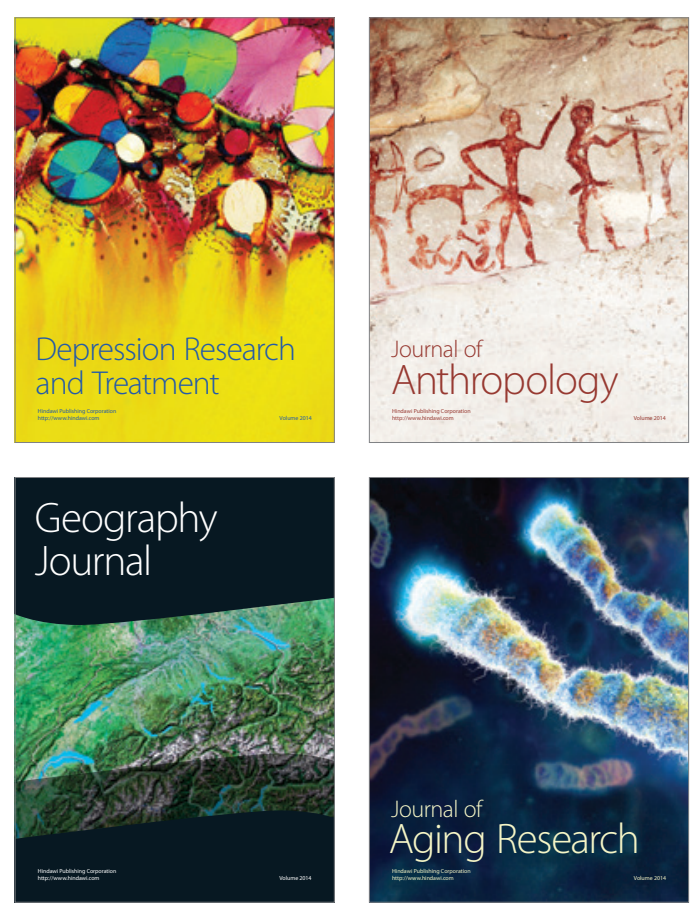

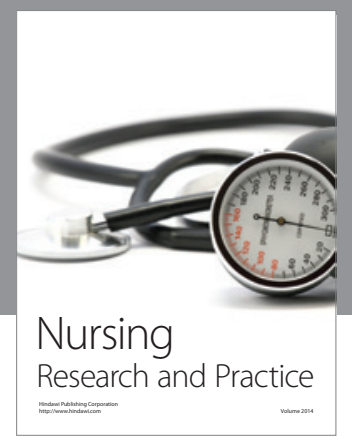

Nursing

Research and Practice

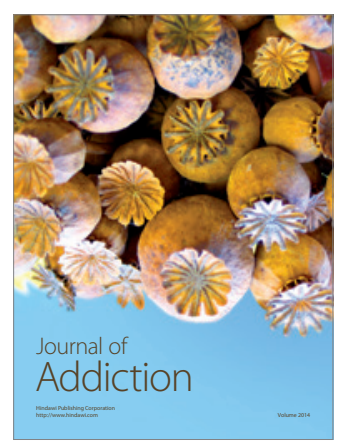

Child Development

Research

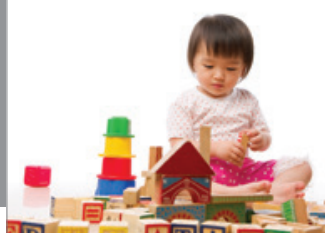

迥
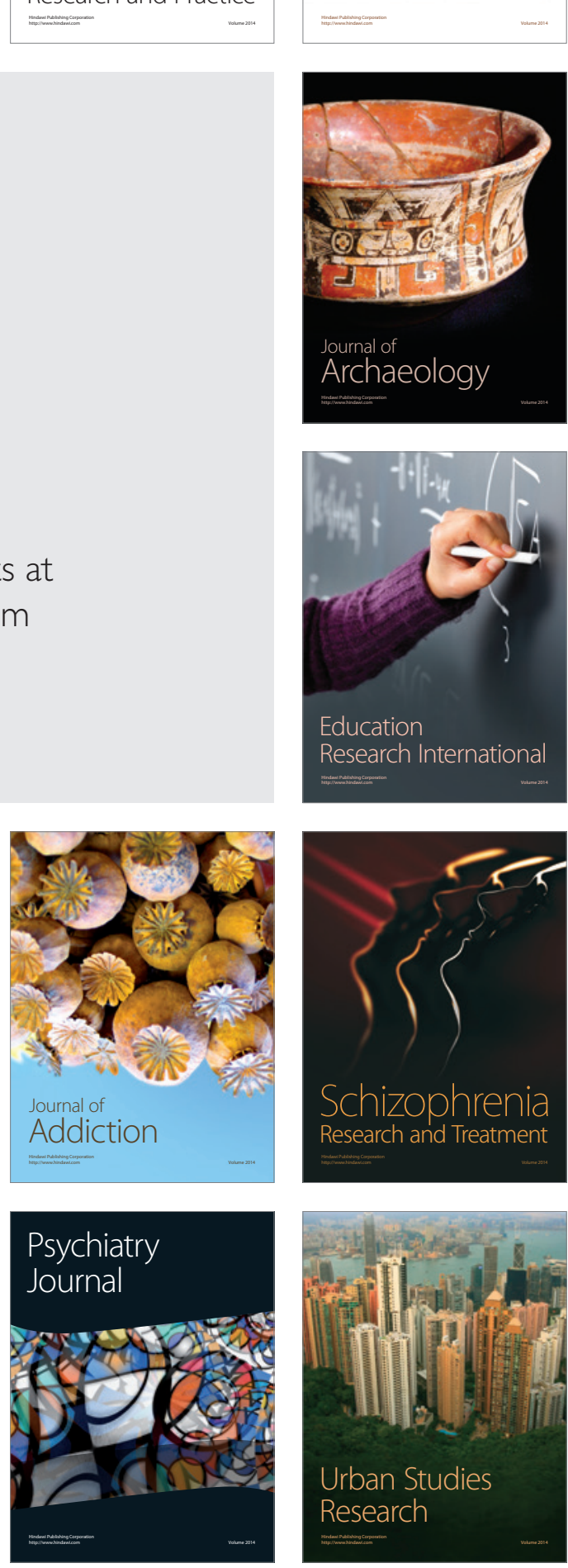